\title{
CUALQUIER PARECIDO CON LA REALIDAD NO ES MERA COINCIDENCIA: ALFREDO BRYCE ECHENIQUE Y LA REESCRITURA DE LA VIDA ${ }^{1}$
}

\author{
Remedios MATAIX \\ Universidad de Alicante
}

Tal vez el intento de abolir los límites que separan la realidad de la imaginación o del deseo haya sido desde siempre uno de los anhelos fundamentales del ser humano. La literatura puede conseguirlo, y lo ha hecho muchas veces, pero en nuestro tiempo quizá ningún escritor lo haga de un modo tan insistente y, además, $\tan$ divertido, $\tan$ conmovedor y $\tan$ creíble como lo hace el peruano Alfredo Bryce Echenique. Su narrativa pone en juego constantemente una fusión entre vida y literatura (más aún: una confusión entre lo vivido y lo escrito) que invita al lector a leer sus novelas no sólo como ficciones que remiten a una verdad sobre la naturaleza humana en general, sino también como confesiones reveladoras de la verdad de un individuo concreto: su autor. Además, cuando en 1993 Bryce publicó sus memorias con el título Permiso para vivir (Antimemorias) -la única de sus obras en que se firma explícitamente el llamado Pacto Autobiográfico entre autor y lector (Lejeune, 1975)-, los lectores que esperaran poder descubrir el proceso de «invención» seguido por el autor desde lo autobiográfico hacia lo literario quedarían defraudados: ese proceso sigue oculto. Las Antimemorias casi nada iluminan en esa dirección, hasta tal punto que algunos de los retazos de la vida de Bryce que ofrecen sus páginas parecen una versión distinta (y no muy distin-

' Una versión abreviada de este texto constituyó la intervención de la autora en el Congreso «Escriptura autobiográfica» celebrado por el Departamento de Filología Catalana de la Universidad de Alicante en diciembre de 1999. 
ta) de las peripecias vividas por los personajes de sus novelas publicadas hasta entonces, Julius, Pedro Balbuena, Martín Romaña o Felipe Carrillo. Y todo hace pensar que eso responde a una estrategia consciente que elige su «lugar como escritor» exactamente en esa frontera difusa que separa y une a la vez la realidad y la ficción, lo que permite interpretar la obra de Bryce en conjunto como uno de los mejores ejemplos contemporáneos de ese fenómeno que se ha conceptualizado por la crítica especializada como «estereografía» o creación de un «espacio autobiográfico» (Catelli, 1991); es decir, como paradigma de la extensión al conjunto de una obra del pacto autobiográfico, a través de una cuidada estrategia que consigue imponer el artificio literario como no-artificio ${ }^{2}$. La obra literaria se ha definido en esos casos como «el espacio donde el escritor emprende la construcción del yo en conexión con algo previo (...) y proclama, para narrar su historia, que él o ella fue aquello que hoy escribe» (Catelli, 1991, 11). Creo que esa misma definición es también una de las mejores descripciones que puedan darse de la narrativa de Bryce, aunque pocas veces ha sido visto así por la crítica. Intentaré explicar más detenidamente todo esto, aplicándolo a su caso que, como digo, me parece un ejemplo magnífico de esa estrategia de autor que diseña las coordenadas con las que desea que sea leído el conjunto de su obra, de acuerdo con la inteligente observación por su parte de que, desde el punto de vista del lector, una autobiografía propiamente dicha y una autobiografía ficticia no constituyen fenómenos literarios diferentes.

Desde su primer libro, el volumen de cuentos Huerto cerrado (1968) -que empezó a escribir «ante un espejo, para que fuera de verdad» (Bryce, 1985, 66)-, hasta la reciente (e inclasificable) Guía triste de París (1999), Alfredo Bryce ha fundido de un modo personalísimo literatura y autobiografía, verdad y ficción, tomando materiales de ambos lados de esa frontera y desplegando todas las realizaciones de una peculiar «escritura del yo» que suprime limpiamente las barreras entre lo que fue y lo que pudo o debió ser. «Mis libros son autobiografías que me he inventado», ha declarado siempre sin reparos (Bryce, 1974, 8), pero ha vuelto a explicarlo recientemente, en la «Nota del autor» que sirve de prólogo a su Guía triste de París:

${ }^{2}$ Algo que ha generado en el caso de Bryce una opinión general que acepta, sin cuestionarla, la verdad autobiográfica de sus novelas. Por ejemplo: «Quien lo lee, no sólo quiere mucho a Bryce, sino que le agradece también que tal cariño no surja del engaño, de esas malas artes que usan tantos y tantas para que les quieran quienes leen la transcripción de sus desgracias. Y aunque el lector no conozca a Bryce, no podrá dejar de pensar que su personaje tiene mucho de sí mismo» (Suñén: 1982,5). 
He vivido y escrito ya lo suficiente para saber que, en todo lo que hago y hasta en lo que no hago, despierto o dormido, hay un elemento altamente literario. Esto no hace de mí un poco o nada fiable Don Quijote jugando tenis o sentado en la redacción de un diario. No. Los tiros no van por ahí (...) Sé perfectamente lo que es y puede llegar a ser la realidad y lo que es y puede llegar a ser la fantasía. Y como a la primera suelo encontrarla chata y aburrida, privilegio siempre la segunda y la dejo entrar y circular libremente por donde le dé su real gana, en cualquier circunstancia o momento, incluso dormido, lo juro. La fantasiosa ficción baña, pues, todo lo que hago y no hago, y creo que ni yo mismo me reconocería jugando tenis de forma totalmente tenística, o sentado en la redacción de un diario de forma exclusivamente periodística (Bryce, 1999, 7).

Esa combinación de materiales es, por tanto, una operación que Bryce lleva a cabo con toda naturalidad y en todas las vertientes de su obra. Novelas y cuentos contienen elementos que remiten de inmediato a la biografía del autor, pero, como ha subrayado José Luis de La Fuente, esa presencia de lo autobiográfico es determinante también en sus ensayos y crónicas recogidos en volúmenes como $A$ vuelo de buen cubero (1977), Crónicas personales (1988) o A trancas y barrancas (1996). No en vano recogía en este último una cita de los Essais de Montaigne, «Soy yo mismo a quien retrato e intento dar un conocimiento no de las cosas sino de mí mismo»: «Su defensa de las ideas del escritor francés -comenta el crítico- le sirve para la reivindicación de la concepción del género ensayístico que practica desde hace años» (De la Fuente, 1998, 131). Pero incluso en la práctica de esos otros «géneros» que también cultiva profusamente Bryce, las conferencias y las entrevistas, no sólo subraya constantemente el contenido autobiográfico de sus novelas, sino que incluso se complace en repetir la idea de que sus libros le han «ocurrido» después de escribirlos, a modo de predicciones o autobiografías por anticipado. Por ejemplo, en una célebre conferencia publicada después con el significativo título de «Confesiones sobre el arte de vivir y escribir novelas», confesaba:

La literatura se ha ido convirtiendo en mi vida, absolutamente, hasta el punto de que algunas de mis novelas, sobre las cuales han dicho que son profundamente autobiográficas, se han convertido, en realidad, en novelas de anticipación de cosas que me iban a suceder fatalmente, sobre las cuales hay testigos (...) Después de un congreso de escritores en la Universidad de Berkeley me sucedió exactamente, ante la vista y la presencia de todos los demás escritores, un capítulo entero de Tantas veces Pedro. Un capítulo entero me sucede en un aeropuerto varios años después... ese es el motivo por el cual se dice que soy un hombre que escribe eternamente su biografía. (...) Todos mis personajes se han ido convirtiendo en apoderados míos, en alter egos míos (...) Por eso en [La vida exagerada de] Martín Romaña hice una tentativa última de des- 
vincularme de la crítica, poniendo en actividad a un personaje llamado Alfredo Bryce Echenique cuya vida se va contando en la novela al pie de la letra (...) Pero desgraciadamente José María Castellet, al presentar la novela en Barcelona, dijo que no, que no era tal cosa, que no había dos personajes, que era un caso típico de esquizofrenia. Entonces, claro, es una cosa muy difícil para mí ir desvinculando la realidad y la ficción (Bryce, 1985, 65 y 71).

Sin duda no faltan en esa novela (como en las demás) momentos inquietantes en el sentido que apuntaba Castellet, ya desde la primera página, donde Bryce explota esa predisposición del lector a identificar al autor con su personaje narrador-protagonista, no sólo por las numerosas coincidencias circunstanciales entre ambos (los dos peruanos en Europa, los dos escritores y los dos enredados en la tarea de narrarse entre las peripecias de una vida «exagerada»), sino además porque el personaje, Martín, se compromete a comportarse como si fuera el autor: «Me llamo Martín Romaña y ésta es la historia de mi crisis positiva», leemos en la primera línea de la novela, pero inmediatamente se añade: «Cabe advertir que el parecido con la realidad de la que han sido tomados los hechos no será a menudo una simple coincidencia, y que lo que intento es llevar a cabo, con modestia aparte, mucha ilusión y justicia distributiva, un esforzado ejercicio de interpretación, entendimiento y cariño multidireccional, del tipo a ver qué ha pasado aquí (...) Por lo demás, altero, cambio o mantengo los nombres de los personajes. Y también los suprimo del todo. Creo que me entiendo, pero puedo agregar que hay un afán inicial de atenerme a las leyes que convienen a la ficción, y pido confianza» (Bryce, 1981, 13-14).

La obra entera de Bryce ha sido construida sobre esa misma base ambivalente -el autor ofrece ficción pero reclama confianza-y, así, permite recorrer toda la variedad posible de discursos del yo. Arriesgo una tipología: en su obra encontramos unas verdaderas (?) memorias en Permiso para vivir, relatos de ficción con base autobiográfica como los de aquel Huerto cerrado, los de La felicidad ja ja (1974), Magdalena peruana (1986) o Guía triste de París; crónicas periodísticas y escritos sobre viajes y otros temas reunidos bajo el significativo título de Crónicas personales (1988) y, sobre todo, abunda la llamada «novela personal» ${ }^{3}$, categoría a la que podemos adscribir sin dificultades Un mundo para Julius (1970), Tantas veces Pedro (1977), La vida exagerada de Martín Romaña (1981), El hombre que hablaba de Octavia de Cádiz (1985), La última mudanza de Felipe Carrillo (1988), No me esperen en abril (1995), Reo de nocturnidad (1997), e

${ }^{3}$ Es decir, aquellos textos que no cumplen el pacto autobiográfico porque la relación autor-protagonista es sólo de semejanza en el plano del enunciado (el personaje como máscara del autor), pero que permiten intuir una relación de identidad en el plano de la enunciación ( $c f r$. Lejeune, 1975, 52). 
incluso La amigdalitis de Tarzán (1999), donde el recurso a una forma típica de la escritura confesional -la correspondencia íntima entre amantes-otorga al texto un valor de autenticidad que, para el tema que nos ocupa, hace casi insignificante el hecho de que el protagonismo de la novela recaiga esta vez (es la única en la obra de Bryce) en el personaje femenino. Todos ellos son, efectivamente, textos de ficción, regulados por un pacto novelesco, en los que, sin embargo, el autor ofrece numerosas «pistas» para hacernos sospechar que se da una identidad entre él y su personaje principal, aunque haya preferido negar esa identidad o simplemente no afirmarla. Son textos que quizá sería mejor calificar como autobiografías noveladas, para hacer hincapié en el sustantivo de la denominación, pero, en cualquier caso, lo importante es que la escritura de Bryce Echenique elabora unos textos en los que vida y literatura interactúan, se rehacen y se revisan mutuamente, explorando y entrecruzando las distintas dimensiones del hecho literario: ficcional, realista y autobiográfica.

Precisamente es la originalidad que brinda esa riqueza de discursos del yo lo que constituye la característica más marcada de la obra de Bryce Echenique, y uno de los rasgos que la singularizan en el marco de la literatura hispanoamericana contemporánea. Él mismo así lo reconoce ${ }^{4}$, pero lo que me interesa destacar es que de ese carácter marcadamente vivencial surgen otras de las características fundamentales de su obra: el humor constante que brota de los conflictos de una vida exagerada en la que el yo se observa actuar, y el carácter autorreflexivo que presenta su narrativa, en un doble sentido: por una parte, porque una novela se «refleja» en la otra, porque un personaje recuerda a otro y porque una aventura alude a otra ya narrada, la completa o la reescribe, y además, por el autoanálisis que ejerce sistemáticamente el narrador-protagonista o el narrador a través del protagonista, para emprender una profunda reflexión centrada en los aspectos

‘ «Ya hoy, con cierta perspectiva, veo a aquellas grandes figuras del «boom» [García Márquez, Vargas Llosa] como grandes escritores que trataron grandes temas colectivos, mientras que la literatura que viene después, en la que me sitúo yo mucho más, es una literatura en la que lo individual triunfa sobre lo colectivo, ¿no?, empieza a hablar el héroe individual, el hombre latinoamericano, el antihéroe ciudadano y su forma de estar en la vida, el hombre con toda su fragilidad y su sentimentalismo; entra la cultura media, entra el cine, la canción, el bolero, qué sé yo... Abandonamos el mundo de los grandes hechos por el mundo de la vida cotidiana. En ese sentido probablemente yo creo que me separé de ellos, ¿no? Tomé todo lo bueno pero no me dejé avasallar por ellos porque no era ése mi camino (...)Yo creo que la literatura mía es una visión de mi vida, de lo que ha sido mi vida, antes que de los grandes temas o las «cuestiones colectivas», como se decía entonces. A mí me interesa mucho más cómo se viven los encuentros y desencuentros, los personajes desgarrados entre dos mundos, que viajan continuamente y en todas partes se sienten como en casa aunque entran un poco con el pie izquierdo, ¿no? Me he reído con cariño de todo esto (...) A Mario Vargas Llosa, siempre tan preocupado por los grandes temas colectivos, le impresionaba que yo perdiera el tiempo con mi interés por lo cotidiano y por la vida privada...» (Bryce, 1994). 
emocionales del sujeto y vinculada a sus lugares de la memoria, individuales (colegios, viajes, ciudades, casas) o colectivos (la Lima de entonces, el París literario, el Mayo del 68, Cuba y la Revolución).

El «método» como escritor que Bryce confiesa practicar incluye, desde luego, lo autobiográfico -es «experiencia, información e imaginación, más la observación y el aprendizaje de la propia vida» (Bryce, 1994)-, e incluso desde el punto de vista formal o estilístico, es ese componente lo que determina su narrativa: la «oralidad» (escribir como se habla), uno de los mayores intereses del autor, puede considerarse un elemento más de ese discurso del yo conversacional, digresivo, nostálgico y humorístico, cuya proximidad estilística contribuye a hacer creer que quien así habla y escribe no puede ser más que real. Lo explica el autor:

Me ha obsesionado siempre la oralidad como una cosa absolutamente peruana. Yo creo que los peruanos son maravillosos narradores orales y que son seres que reemplazan la realidad, realmente la reemplazan, por una nueva realidad verbal que transcurre después de los hechos (...) Esto para mí fue una obsesión y quise llevar a mi literatura esa oralidad, esa capacidad de arreglar la realidad, de burlarse de ella, finalmente, de recuperarla, de ser el observador que se observa a sí mismo observando, y añadirle un toque de humor a esto, porque el humor es un elemento importantísimo para soportar una realidad insoportable (...) Pero, claro, cuando uno está contando una cosa, dice, de pronto: «Y esto me recuerda que...» e interrumpe, se interrumpe. Eso también trato de llevarlo a la novela, las digresiones, con gran peligro de que luego se señale una ausencia de nexos lógicos, una falta de orden. Pero ése es el desorden vital que también trato de incorporar a lo que escribo. Para mí esto es algo vivido, algo que además me interesa mucho, y en ese sentido, pues es una experiencia autobiográfica (Bryce, 1993 bis, 630-633).

Sólo así cabe entender la complejidad estructural de las novelas de Bryce, que aspiran a reflejar una realidad contemporánea (y muchas veces a criticarla), incluyendo en el texto todos los estímulos que pueden conformar una vida: recuerdos, lecturas, cartas, letras de canciones, diarios, citas cinematográficas, referencias e incluso fragmentos de otras obras del personaje propuesto como autor del texto que estamos leyendo, etc., etc.; es decir, cualquier cosa que contribuya a expresar esa extrañeza ante la existencia que sienten sus personajes. De acuerdo con estas premisas, el sujeto analizado y analizante, protagonista perpetuo de las obras de Bryce, no responde a los grandes modelos de héroe memorialístico así considerados por el autor (Stendhal, Proust, Neruda, el Inca Garcilaso): el antihéroe entrañable tipo Bryce Echenique, aunque es protagonista de la narración y sus peripecias, en el fondo no parece ser el centro de la realidad que narra, 
sino más bien su descentramiento. Es un sujeto excéntrico, enternecedor, vulnerable y tragicómico, que vive una vida también tragicómica en la que, más que provocarlos, asiste a unos acontecimientos que le sobrevienen: un yo que obser$v a$ su vida convertida en relato, y en un relato que irá ajustándose a distintos moldes que proporciona la vida real del autor (desde el de aprendiz de escritor hasta el de profesor universitario, por ejemplo). Pedro Balbuena, de Tantas veces Pedro fue el primer ejemplo de ese «antihéroe total y tragirridículo» que será constante: un hombre confundido que «da vueltas a esos temas de la amistad, el amor, los afectos, y los pone patas arriba»; un hombre que -como el autor cuando escribió la novela- tiene cuarenta años y se declara escritor, aunque «acaba sin poder redactar ni su vida ni su obra, porque se le confundieron absolutamente las dos cosas», confusión que, subraya Bryce, «es algo que a mí me ha apasionado siempre» (Bryce, 1994), y que reaparece en su por ahora último libro, como una interesante irrupción reflexiva del autor en medio de un relato:

Pongo en mis escritos lo que no pongo en mi vida. Por eso creo que no los termino nunca. Y no pongo en mi vida lo que pongo en mis escritos. Por eso es que vivo tan poco y tan mal (Bryce, 1999, 75).

Pero creo que sus Antimemorias nos daban la clave para resolver la cuestión, y entenderla, como avanzábamos antes, como una estrategia de autor:

Ahora me hace mucha gracia contar historias y que la gente me diga que me las he inventado. Luego, cuando las escribo en un libro, me dicen que son autobiográficas. Definitivamente, la gente no se pone de acuerdo conmigo, con una excepción: los escritores. Ellos saben, o intuyen, que en el arte la verdad está en el estilo (Bryce, 1993, 81. La cursiva es mía).

«Hacer y, al hacer, hacerse» se ha propuesto como divisa de la escritura autobiográfica (Gusdorf, 1991, 16): narrarse es también construirse. Ese mismo principio puede considerarse, a mi entender, no sólo la clave estilística de la narrativa de Bryce, sino su núcleo semántico, de donde surge la fuerza de atracción que ejerce su mensaje y, por lo tanto, una de las claves de su éxito: como se sabe, Bryce Echenique es uno de los autores hispanoamericanos más premiados, más traducidos y, lo que es más importante, más leídos actualmente.

Casi parece innecesario preguntarse si es la propia cosmovisión de nuestro tiempo lo que permite explicar el éxito contemporáneo de este tipo de literatura: la cualidad de lo ficticio, la invención o la imaginación son las características canónicas de la literatura, y, sin embargo, la práctica literaria de numerosos autores contemporáneos parece insistit precisamente en lo contrario, en el principio de sinceridad de quien escribe, y en el de la suspensión voluntaria del descrei- 
miento por parte de quien lee, que así dota de un sentido verdadero al texto. Quizá la esencia de la autobiografía, ese intento de articular mundo y yo a través de un texto, coincide con el eje vertebrador de las inquietudes más íntimas del último fin de siglo - que parecen desplazarse hacia esos centros de atención- y con la consecuente evolución de la literatura, que se aleja de los grandes relatos míticos o totalizadores para acercarse más a lo cotidiano o a lo humano en singular. Pero también podemos pensar que esa esencia del género autobiográfico confluye con una corriente más intemporal, como es el interés que nos despierta toda experiencia humana auténtica, o que percibimos como auténtica.

Tal vez buena parte del éxito de la obra de Alfredo Bryce está en haber sabido apuntar hacia ahí, y acertar, desplegando una estrategia autobiográfica global que permite al escritor dirigirse a un público interesado de antemano por el juego comunicativo que propone. Se trata, claro, de una estrategia de tipo pragmático que, como ha reclamado últimamente la crítica, constituye la clave de la escritura autobiográfica: el quid de la cuestión reside, no ya en el plano de los vínculos del texto con la realidad (veracidad / ficcionalidad), sino en el terreno de las relaciones entre los textos y sus intérpretes. Y consiste en la capacidad de obtener rendimiento, por supuesto, de ese valor autentificador que tiene la escritura por sí misma en tanto que registro simbólico, pero además, de lo que se ha llamado «realismo intencional», es decir, de la tendencia natural por la que el lector tiende a aproximar el universo del texto al suyo propio y «asume espontáneamente la «seriedad» de un texto escrito que, aunque sea ficticio en su origen, se presta a una decodificación realista». Ésta consistiría en «la tarea hermenéutica de dotar de un sentido real al texto, iluminando su campo de referencia interno e inmanente desde el campo de referencia externo», que no es otra cosa que la propia experiencia vital del lector (Villanueva, 1993, 26). Tal propuesta refuerza ese sentido contractual que ya Philippe Lejeune en su célebre libro de 1975 intuía para la naturaleza básica del género autobiográfico, definible, efectivamente, no tanto por sus elementos formales cuanto por el pacto de lectura que implica.

En realidad, sólo un lector analítico, precavido o deliberadamente atento sólo al artificio literario hace una lectura exclusivamente antirrealista de un texto, de cualquier texto. Los lectores que en circunstancias «normales» no recibimos las obras literarias sólo como objeto artístico, sino como concentrados de experiencia que ofrecen señales de vida y remiten al mundo que las origina, proyectamos nuestra propia experiencia de la realidad sobre esas señales de la ficción leída, y viceversa, y participamos así, quizá inconscientemente, en una situación comunicativa en la que se da por supuesta la sinceridad del autor. Y no me refiero, claro, a una identificación ingenua (o patológica) del tipo Don Quijote o 
Emma Bovary. No, como diría Bryce, los tiros no van por ahí. Me refiero a esa otra identificación (¿voluntaria?) por la que, a veces, permitimos que un texto nos ofrezca una íntima revelación, o, al menos, que nos conmueva y genere resonancias o interrogantes en alguno de nuestros más menudos pliegues interiores.

Desde este punto de vista, es evidente que el principio autobiográfico no se traiciona por el empleo en la narración de otras personas gramaticales (un «tú»o un «él») si el lector cree que traducen una misma referencia -el yo-y si el lector cree que responden a ese ejercicio necesario de trasladar el propio sujeto a la posición de objeto para poder reconocer sus contornos. Creo que éste es el caso de las novelas de Bryce. El autor escribe su obra dentro de un espacio autobiográfico global cuidadosamente elaborado, aunque en ocasiones decide codificar su yo en otros «yo» que narran en primera persona, en un «él» narrado por otro, o bien decide desenmascararlo en unas Antimemorias como realización explícita de la autodiégesis, para la que, no obstante, no renuncia a utilizar los mismos ingredientes que pone en juego en sus ficciones, porque son elementos que forman parte de lo que él entiende por escritura, en general: básicamente, un arte del recuerdo, del recuento y del re-cuento en el que se recupera lo vivido y lo ya escrito mediante una expansión digresiva que se sirve de lo ficcional.

Nora Catelli ha recordado que en 1799 los hermanos Schlegel distinguían, entre los diferentes tipos de autobiógrafos, dos clases opuestas: los que narran -neurótica, exhibicionista, histérica u obsesivamente- la verdad, y los autopseustos, es decir, «los que mienten sobre sí mismos», los que deliberadamente urden la mentira que nos narran (Catelli, 1991:9). Nunca han faltado actitudes escépticas ante el valor de verdad que puede atribuirse a una obra literaria, pero esa distinción es ya para nosotros poco operativa, y no sólo porque la opinión más consensuada entre la crítica es la que entiende que la autobiografía es siempre, en mayor o menor grado, autoinvención, y que el discurso autobiográfico no puede ser verdad aséptica porque es discurso, es decir, elaboración, creación. La dicotomía veracidad / ficcionalidad tampoco sirve para distinguir en la obra de Bryce uno u otro género, porque, entonces, ¿cómo catalogar una obra como sus Antimemorias, definida por el autor como un intento de reflexión autobiográfica, presidida por todas las marcas formales del pacto autobiográfico y gobernada por lo que él llama Ley de la Seriedad (escribir sus memorias cuando todavía su edad le permite recordar, contrastar datos, confirmar hechos), pero que, a la vez, despliega un discurso que constantemente se atribuye a sí mismo caracteres novelescos? Por ejemplo, cuando reflexiona sobre el título:

¿Por qué «antimemorias» como Malraux? Pues precisamente por haber leído demasiado sobre memorias, autobiografías y diarios íntimos, antes de 
ponerle un subtítulo a esta sarta de capítulos totalmente desabrochados en su orden cronológico y realmente escritos «por orden de azar» y «a mi manera» [títulos de las dos partes en que se divide el texto] (...) Malraux dixit que las memorias ya han muerto del todo, puesto que las confesiones del memorialista más audaz o las del chismoso más amarillo son pueriles si se las compara con los monstruos que exhibe la exploración psicoanalítica. Y eso no sólo da al traste con las memorias, sino también con los diarios íntimos y las autobiografías. Las únicas autobiografías que existen son las que uno se inventa, además (Bryce, 1993, 16-17. La cursiva es mía).

O cuando, para enlazar aún más las cosas, presenta el libro con declaraciones como ésta:

Las Antimemorias están escritas en prosa de ficción. Hay capítulos incluso con pequeño desenlace, de ahí que a mucha gente le gusta leerlo como un libro de cuentos, por capítulos sueltos que luego se retoman, porque no tiene un orden cronológico ni nada (...) He comprobado que me es imposible volver a contar una anécdota en un libro. Tengo que crearla de nuevo. EI hecho vivido, vivido está. Hay que volverlo a inventar. Hay que hacerlo explotar para que muestre todos sus rincones, todos sus recovecos. Y también, por qué no, aquello que no fue, aquello que no es (Bryce, 1994).

De hecho las Antimemorias han funcionado en el conjunto de su obra como algo parecido a un «temario», de cuyas sugerencias parecen haber brotado directamente novelas posteriores como No me esperen en abril o Reo de nocturnidad. No tendría mucho sentido, pues, cotejar la biografía de Bryce con sus novelas para saber cuándo «miente», igual que sería absurdo confundir al autor con alguno de sus personajes como equivalente exacto, o intentar un psicoanálisis de Alfredo Bryce Echenique a través de sus novelas. $\mathrm{Y}$ sin embargo, eso ha pasado; al menos si, una vez más, creemos al autor cuando nos cuenta anécdotas como ésta, sobre esa percepción superficial de que es su propio personaje:

El último problema que he tenido ha sido con un crítico italiano, Walter Mauro, que estaba haciendo un trabajo sobre mi obra y que había hecho todo un largo ensayo sobre el complejo de Edipo en Un mundo para Julius y luego comenzó a tratar el complejo de Edipo en La vida exagerada de Martín Romaña. Estaba tan obsesionado con el complejo de Edipo que incluso cuando me presentó en Italia decía el señor Echenique, el señor Echenique, y yo le decía, pero hombre, no mate usted a mi padre; el problema de Edipo lo tiene usted tan enorme que hasta mata a mi padre. Me llamo Bryce Echenique, pero él insistía en decir el señor Echenique, el señor Echenique, y descubrió, para su profunda angustia, que la madre de Julius y la madre de Martín Romaña son dos personajes totalmente diferentes, y vino a preguntarme por qué tenía dos madres. Yo le dije que le iba a dar la dirección de mi madre en Lima, para que 
fuera a ver quién era, cuál era la realidad, y que yo tenía el derecho a fabular como todos los demás escritores... (Bryce, 1985, 71).

Naturalmente, los personajes de Bryce no son uno solo, ni equivalen al autor; le pertenecen por entero, pero no son él, aunque no deje de proponerlos una y otra vez como auténticos alter ego. No quiero decir con esto que Alfredo Bryce practique ninguna impostura, ni que pretenda hacer al lector víctima de una superchería, al contrario: lo que hace es darle exactamente lo que quiere, pues para un lector de hoy difícilmente podría resultar satisfactoria de ese interés natural del que hablábamos antes la narración de una experiencia humana que entendiera la personalidad como un referente preciso e inmutable, o que tradujese la existencia de un yo como entidad compacta y no problemática. Su obra construye un «espacio autobiográfico» porque ficcionaliza peripecias vitales que previamente (o de manera simultánea) el autor ha desficcionalizado y autentificado, remitiéndolas a un referente real o, al menos, no negando la posibilidad de hacerlo. Pero la «verdadera» autobiografía de Alfredo Bryce Echenique, como el autorretrato total de Rembrandt, se encuentra en el punto de fuga de todos sus rostros, de todos sus protagonistas diferentes, de los que él es el denominador común. El sujeto es el resultado de la decantación de su laborioso discurso, de ese espacio autobiográfico global que emprende una representación del yo que para Alfredo Bryce no se define por un solo discurso (sea genealógico, afectivo, social, ideológico, cultural o imaginario), sino por la confluencia de todos ellos en un punto común, «una forma de estar en la vida, una relación particular con el mundo» (Bryce, 1993, 17). Esta convicción encuentra su traducción literaria en una obra donde la sinceridad -o la ficción dicha como verdad- es la regla para que cada nueva novela nos resulte tan familiar, pero sea irrepetible: cada una abre y cierra su historia como un tiempo completo (o incompleto, pero clausurado hasta una posible reescritura posterior).

El proyecto narrativo de Bryce se cumple, pues, como una fascinante aventura de ampliación de los poderes introspectivos y auto-descriptivos de la literatura, planteando una estética de «lo exagerado» que amplifica tanto los actos de vida como los actos de habla, pero hace de esos excesos la práctica central de una escritura del yo creíble. El magnífico escritor que la produce ha sabido aprovechar ese proceso espontáneo de lectura realista que se da en todo lector «normal», para presentar su obra como si fuera un relato no sólo verosímil, sino verdadero, no realista, sino real; algo que construye todo un espacio autobiográfico. El porqué más profundo de esa estrategia quizá lo encontramos en el título que Bryce quiso darle a sus memorias, Permiso para vivir, y en su explicación, como siempre teñida de humor, pero muy seria: 
Hay en la escritura de cada uno de estos capítulos (como en todo aquello que escribe un escritor) un temor oculto: mejor no podía andar mi madre física y psíquicamente, tan joven de cuerpo y de espíritu que sólo aceptaba a la gente joven de edad y de espíritu (más un lord inglés un poquito más joven que ella por novio), cuando de pronto la sorprendió el siglo XIX como único tema de conversación; después, el virreinato, que siempre le gustó tanto, y hoy, con una asombrosa cara de rosa y una salud que está acabando con hijos, enfermeras, inmortales mayordomos, cocineras, empleadas domésticas y ex-empleadas domésticas de nuestros familiares que recogió y acogió (...), hoy la pobrecita de mi madre ya ni reconoce a su hijo Marcel Proust (...) Tal vez cuando sea como mi miedo a ser como mi madre, alguien tenga la bondad de entretenerme leyéndome todo lo que el tiempo se llevó. Tal vez logre reconocerme, sonreírme, cuando ya no logre retener quevedianas lágrimas, o cacas que tampoco supe retener en la infancia, como tuttilimundi. Estaré muerto en vida, o casi muerto (...) De ahí también el título de Permiso para vivir (Bryce, 1993,16).

Por todo eso parece poco probable que el «estilo Bryce» genere escuela, aunque su defensa de un arte más vivencial y menos definido por las modas sí parece haber entrado a formar parte de una atractiva tendencia de la novela hispanoamericana actual, tal vez porque, como ha resumido Antonio Skármeta, «...al fin y al cabo, es su propia vida la cosa más cercana que cada escritor tiene para echar mano» (Skármeta, 1981, 285).

$*$

\section{BIBLIOGRAFÍA CITADA}

BRYCE ECHENIQUE, Alfredo, 1981. La vida exagerada de Martín Romaña, Barcelona, Plaza \& Janés.

- 1985. «Confesiones sobre el arte de vivir y escribir novelas», Cuadernos Hispanoamericanos, $\mathrm{n}^{\circ} 417$; págs. 65-76.

- 1993. Permiso para vivir. Antimemorias, Barcelona, Anagrama.

- 1993 bis. «Confesiones» incluidas como apéndice en Un mundo para Julius, ed. de Julio Ortega, Madrid, Cátedra; págs. 609-635.

- 1994. Transcripción de las respuestas de Alfredo Bryce a una entrevista realizada por Teodosio Fernández, celebrada en la Universidad de Alicante, en enero de 1994.

- 1999. Guía triste de París, Madrid, Alfaguara. 
DE LA FUENTE, José Luis. «Autobiografía: escribir sobre lo vivido y vivir lo escrito», en su Más allá de la Modernidad. Los cuentos de Alfredo Bryce Echenique, Valladolid, Universidad de Valladolid, 1998.

CATELLI, Nora, 1991. El espacio autobiográfico, Barcelona, Lumen.

GUSDORF, Georges, 1991. «Condiciones y límites de la autobiografía», trad. de Ángel G. Loueiro, Suplementos Anthropos, 29; págs. 9-18.

LEJEUNE, Philippe, 1975. Le pacte autobiographique, París, Seuil.

SKÁRMETA, Antonio, 1981. «Al fin y al cabo es su propia vida la cosa más cercana que cada escritor tiene para echar mano», en VV.AA., Más allá del boom. Literatura y mercado, México, Marcha Editores; págs. 263-285.

SUÑÉN, Luis, 1982. «Queremos tanto a Bryce», El País, 28 de febrero, pág. 5.

VILLANUEVA, Darío, 1993. «Realidad y ficción: la paradoja de la autobiografía», en José Romera et al. (eds.), Escritura autobiográfica, Madrid, Visor; págs. 15-31. 